Investigaciones Fenomenológicas, n. 9, 2012, 69-88.

e-ISSN: $1885-1088$

\title{
POR EJEMPLO, TAIWAN: \\ HACIA UNA FENOMENOLOGÍA DE LA CULTURA NACIONAL
}

\author{
Lester Embree \\ Florida Atlantic University, Estados Unidos \\ embree@fau.edu
}

\begin{abstract}
Resumen: La cultura tiene muchas dimensiones, por ejemplo, la del género; pero, ¿qué pasa con la cultura de una nación tomándola como un todo? ¿Se puede uno aproximar fenomenológicamente a este tema? Usando una pequeña nación como ejemplo y utilizando una historia popular, yo debato aquí, en primer lugar, sobre cómo los objetos culturales concretos son diferentes de los objetos naturalistas una vez que estos se abstraen de todas las funciones 0 , mejor, usos que tienen. A continuación, describo Taiwan de modo naturalista: geográficamente, geológicamente, ecológicamente, etc., y, después, antropológicamente, con respecto a cómo ha sido poblada. Dejando de lado la abstracción, lo siguiente es evocar aspectos culturales de esta isla para sus ciudadanos, en términos de religión, cultura alta, sistema social, economía y política. Estos aspectos ciertamente son diferentes para otras culturas nacionales, pero todas ellas tienen aspectos de este tipo y partiendo de este ejemplo uno podría ir más allá, a la cultura nacional en general.
\end{abstract}

Palabras clave: Fenomenología, cultura nacional, actitud naturalista, ecología, antropología, religión, arte, economía, política.

\begin{abstract}
Culture has many dimensions, e.g., that of gender, but what's up with cultures of whole nations? Can such an issue be approached phenomenologically? Using a small nation as an example and drawing on a popular history, I first discuss here how concrete cultural objects are different from naturalistic objects, after removing from them all the functions or uses they have. Then, I naturalistically describe Taiwan geographically, geologically, ecologically, etc. and then anthropologically with regard to how it has been inhabited. Leaving aside abstraction, I then evoke cultural aspects of this island for its citizens, in terms of religion, high culture, social system, economy and politics. These aspects are certainly different for other national cultures, but they all have similarities, and starting from this example we could go furhter, towards a national culture in general.
\end{abstract}

Keywords: Phenomenology, national culture, naturalistic attitude, ecology, anthropology, religion, art, economics, politics.

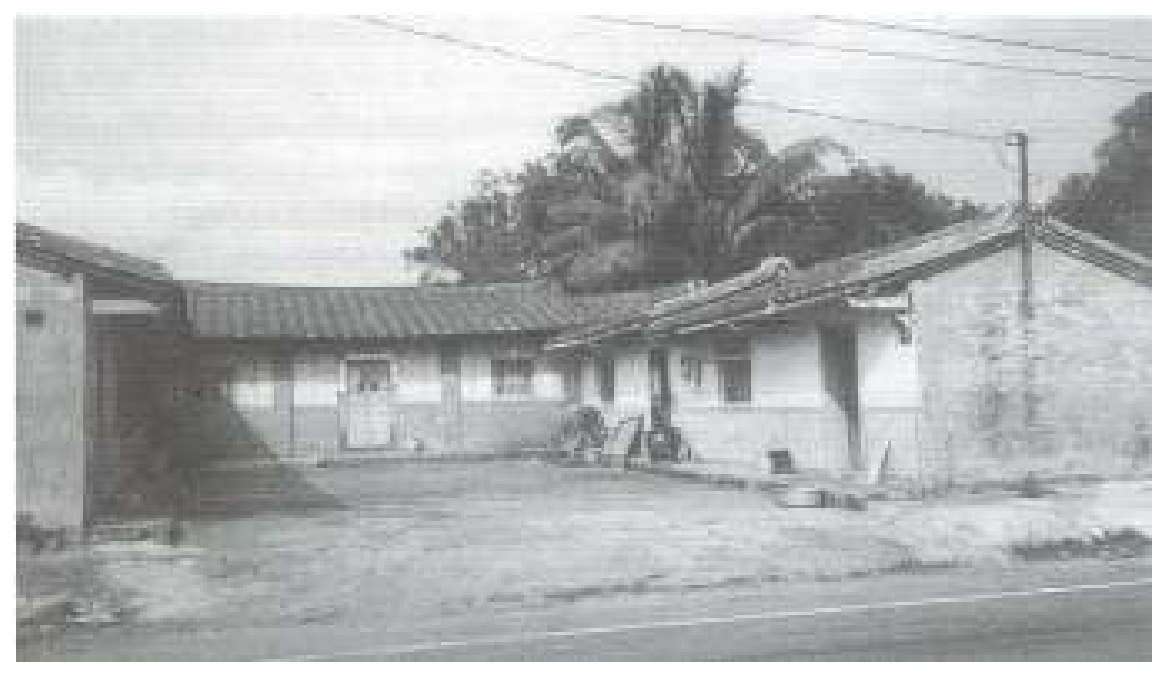

Vivienda aldeana tradicional para una familia numerosa ${ }^{1}$ 


\section{INTRODUCCIÓN}

En ensayos anteriores he investigado dimensiones de la cultura humana que incluyen la clase social, el ambiente, la etnicidad, el género y la generación ${ }^{2}$. Hubo decepciones entre los colegas durante las presentaciones orales de estos ensayos porque no me ocupé de lo que llamo aquí "cultura nacional". Las sociedades consideradas como un todo son mencionadas en "A Gurwitschian Model for Explaining Culture or How to Use an Atlatl" ("Un modelo gurwitscheano para explicar la cultura o cómo usar un atlatl) ${ }^{3}$ y hay algunos casos de comparación entre culturas nacionales en "The Constitution of Polite Fictions" ("Ficciones de cortesía") ${ }^{4}$. Ésta es mi primera investigación directa acerca de la nacionalidad. En lo esencial, explora la superficie a la vez que todavía exige investigaciones más profundas ${ }^{5}$.

A pesar de la discusión que después iniciaré sobre los objetos naturalistas y los objetos y situaciones culturales, y a pesar de los comentarios a lo largo del texto, tal vez algunos colegas, particularmente en el ámbito de la filosofía, piensen todavía que todo esto es una gran cantidad de datos de la ciencia social o, si son más sofisticados, que lo son de la ciencia cultural y tal vez se pregunten qué puede tener que ver esto con la fenomenología.

Qué sea la fenomenología ha sido, precisamente, un interrogante constante en su centenaria y planetaria tradición. La cuestión se complica por el hecho de que parece haber elementos de fenomenología en alrededor de tres docenas de disciplinas cognitivas, valorativas y prácticas $^{6}$ y de que al menos el núcleo filosófico de la tradición ha pasado por una serie de formas y etapas en su histo-

\footnotetext{
${ }^{1}$ Gary Marvin Davidson / Barbara E. Reed (eds.), Cultures and Customs of Taiwan, Westport / Londres, Greenwood Press, 1998, p. 126. En lo que sigue, este libro será citado con la sigla CCT.

${ }^{2}$ Los ensayos en torno a dichas dimensiones han sido reunidos y traducidos en Lester Embree, Fenomenología Continuada: Contribuciones al análisis reflexivo de la cultura, Morelia, Jitanjáfora, 2007.

${ }^{3}$ En Josep Claude Evans / Robert S. Stufflebeam (eds.), To Work at the Foundations: Essays in Memory of Aron Gurwitsch, Dordrecht, Kluwer Academic Publishers, 1997, pp. 141-171.

${ }^{4}$ En Ernst Wolfgang Orth / Chan-Fai Cheung (eds.), Phenomenology of Interculturality and LifeWorld, Munich, Verlag Karl Alber, 1998, pp. 209-228.

${ }^{5}$ Cuatro colegas en Taiwan han leído este ensayo a petición mía. Uno de ellos es chino y tanto su madre como su padre provienen del continente; otro es Hakka; otro es aborigen; el último es taiwanés de ascendencia Han. Todos ellos parecen estar de acuerdo en que las cosas cambian muy rápidamente, pero que, a pesar de eso, el ensayo parece capturar la nacionalidad tradicional de Taiwan.

${ }^{6}$ En lo que concierne a las disciplinas fuera de la filosofía en las que hay colegas que se consideran fenomenólogos, pueden contarse hoy treinta y seis: arquitectura, ciencia cognitiva, comunicología, asesoramiento (counseling), antropología cultural, ecología, economía, educación, inglés, estudios étnicos, etnología, etnometodología, estudio del arte fílmico, francés, geografía, ciencias del comportamiento, ciencia social, hermenéutica, historia, lingüística, derecho, literatura, antropología médica, medicina, musicología, enfermería, filosofía de la religión, ciencia política, psiquiatría, psicología, psicopatología, educación religiosa, trabajo social, sociología y teología.
} 
ria, a saber, la fenomenología realista, constitutiva, existencial, hermenéutica y hoy, quizás mundo de la vida.

Tras haber ponderado este problema de una manera que no es específica de ninguna disciplina determinada, he llegado al resultado de que la fenomenología, genéricamente, es (a) reflexiva, (b) descriptiva y (c) valoradora de la cultura. La última determinación mencionada contrapone a la fenomenología, en particular, con la tradición del positivismo y esto debería resultar claro por las referencias a usos, a voliciones, a valores y a valoración en un sentido amplio; todas estas referencias son fundamentales para la cultura $y$, sin embargo, la investigación naturalista hace abstracción de ellas.

Decir que la fenomenología es descriptiva equivale a decir, en primer lugar, que no es primariamente explicativa o argumentativa $y$, en segundo lugar, que sus resultados son no sólo a veces fácticos, sino a menudo eidéticos. De esta manera, si bien proporcionaré aquí una cantidad considerable de hechos científico-culturales acerca de Taiwan, el propósito es trabajar un ejemplo de lo que supone la pertenencia a una nacionalidad en general como uno más de los aspectos en los que consiste vivir en un mundo de la vida concreto (Lebenswelt).

Decir que la fenomenología es reflexiva equivale a decir que observa encuentros y cosas-en-cuanto-encontradas, tanto a nivel individual como colectivo, que lo hace de una manera operacional y habitual/tradicional y que incluye análisis mediante los cuales se distinguen voliciones y usos, valoraciones y valores, y creencias y características de creencia, así como sus modos y formas positivos, negativos y neutrales, intrínsecos y extrínsecos, etc.

Para los filósofos a quienes interesa la fenomenología especificada para su disciplina, puede sugerirse que la clarificación del concepto básico de cultura nacional es importante para la teoría de las ciencias culturales. Los colegas que provienen de otras disciplinas quizás encuentren este análisis también relevante para las diferentes perspectivas de sus disciplinas. Por tanto, puede hablarse de "análisis reflexivo" y el presente ensayo que aquí se ofrece es un ejemplo de ello.

El contenido del presente ensayo es de dos tipos. El contenido fundamental se ocupa de cómo puede abordarse la cultura nacional de manera fenomenológica y el restante, que es más extenso, concierne a la nación de Taiwan tal como la he encontrado indirecta y directamente. Estuve allí tres veces para dar conferencias y cursos y tanto los colegas como los estudiantes de enfermería, 
filosofía y psicología no sólo me han mostrado, sino que también han descrito para mí, diversos aspectos de su país. He visto además videos y he leído varios libros al respecto, incluyendo Forbidden Nation: A History of $\operatorname{Taiwan}^{7}$ y, sobre todo, Cultures and Customs of Taiwan ${ }^{8}$. Este último es el compendio de una cantidad considerable de historia, lingüística, ciencia social, etc., y recurriremos ampliamente a él, pero poniendo el énfasis y disponiendo el orden de la exposición de manera algo diferente.

No estoy informado muy a fondo acerca de Taiwan, pero mi base me parece adecuada para comenzar. Ello se debe en gran medida a que, tal como me sucedió a mí, se puede inducir al lector a recordar y a figurar (feign) aspectos de otras naciones como medios orientados a la clarificación de una diversidad de tesis generales. Tengo la esperanza de que otros, al igual que yo mismo, puedan más tarde corregir y refinar mi método y mis hallazgos. Puedo tratar de decir algunas cosas de manera fenomenológica ${ }^{9}$. $Y$ puedo repetir que empleo Taiwan como un ejemplo de lo que es una cultura nacional y que podría haber usado en su lugar otra nación como ejemplo si hubiera estado familiarizado con ella de modo análogo.

\section{Pensando más allá del encuentro directo}

Voy a comenzar sirviéndome de un ensayo que muestra que Edmund Husserl avanza más allá de la epistemología y que aborda la teoría de la acción ya en su primer texto filosófico (pues consideraba sus Logische Untersuchungen [1900-1901] "pre-filosóficas"), es decir, en Ideen zu einer reinen Phänomenologie und phänomenologischen Philosophie, primer volumen $(1913)^{10}$. Tras una

\footnotetext{
7 Jonathan Manthorpe, Forbidden Nation: A History of Taiwan, New York / Houndmills, Palgrave MacMillan, 2002.

${ }^{8}$ Ver nota 1 , in supra.

Dado que este informe tiene ya una década y Taiwan está cambiando velozmente, he obtenido información del artículo de la Wikipedia sobre Taiwan, y añadí algunos detalles que tomé de allí. También debo mencionar que la conferencia de Elmar Holenstein, "Complex Cultural Traditions" (en Chinese University of Hong Kong, mayo de 2004), me ha enseñado a ser escéptico con respecto a las nociones simplistas y dogmáticas acerca de lo que son los mundos culturales y, en especial, a no reducirlos completamente a sus orígenes, aun cuando el presente esté siempre afectado en gran medida por el pasado.

${ }^{9}$ Para una clarificación de mi enfoque, véase Lester Embree, Análisis reflexivo. Una primera introducción a la investigación fenomenológica / Reflective Analysis. A First Introduction into Phenomenology, Morelia, Editorial Jitanjáfora, 2003 (trad. al castellano de Luis Román Rabanaque). El texto original en inglés es Reflective Analysis, Bucarest, Zeta Books, 2006.

${ }^{10}$ Lester Embree, "Some Noetico-Noematic Analyses of Action and Practical Life", en John Drummond / Lester Embree (eds.), The Phenomenology of the Noema, Dordrecht, Kluwer Academic Publish-
} 
sección dedicada a presentar esta cuestión, consagraré la siguiente a exponer el pensamiento de Aron Gurwitsch en torno a la vida práctica. Su ejemplo típico es el de un tintero sobre una mesa. Cuando un objeto semejante es un tema en el foco de la experiencia, en su trasfondo se encuentran ciertos elementos, tales como las hojas de papel, los libros y el escritorio, que tienen alguna relación con él y que forman su "campo temático", mientras que otros, tales como la casa que se ve a través de la ventana, no tienen normalmente nada que ver con él y son, por consiguiente, "marginales".

Los elementos mencionados son útiles, lo que quiere decir que se usan "con el fin de" realizar alguna otra cosa como, por ejemplo, escribir una carta y, por tanto, tienen un uso. Han sido llamados "objetos funcionales" por Wolfgang Köhler y, en mi opinión, su mejor denominación es "objetos de uso"; se correlacionan intentivamente con el componente volitivo de su encuentro. En una situación práctica tal puede haber otras personas junto con uno mismo, quizás discutiendo lo que ha de incluirse en la carta y cumpliendo, por consiguiente, ciertos papeles, que son también maneras de tener usos. Los objetos de uso son una de las tres especies de objetos culturales; los otros dos son los objetos valorativos y los objetos cognitivos.

¿Cómo es posible ampliar este enfoque a una nación entera como Taiwan partiendo de un caso tan reducido y directamente encontrable? Tres pasos son necesarios. En primer lugar, se debe procurar trascender el caso particular recurriendo a una buena cantidad de juicios basados en la lectura de libros y en el examen de imágenes, así como en observaciones personales y en lo que la gente informa. Esto se asemeja al modo en que puede trascenderse la interacción cara a cara, según Alfred Schutz, a fin de relacionar, mediante el uso de tipos ideales, a los "contemporáneos" actualmente vivientes pero ausentes, a los "predecesores" ya muertos y a los "sucesores" aún no nacidos y, gracias a ello, captar la estructura más general de un mundo social cualquiera.

En segundo lugar, es necesario enfatizar que los objetos no valen para individuos sino para grupos, desde la familia hasta la nación. Esbozaremos ahora los grupos componentes para el caso de Taiwan. Las cuestiones enfocadas aquí

ers, 1992, pp. 157-210. Cfr. Lester Embree, "Advances Concerning Evaluation and Action in Husserl's Ideas II", en Thomas Nenon / Lester Embree (eds.), Issues in Husserl's "Ideas II", Dordrecht, Kluwer Academic Publishers, 1996, pp. 173-198; reimpreso en Dermot Moran / Lester Embree (eds.), Phenomenology: Critical Concepts in Philosophy, 5 vols., Londres, Routledge, 2004, vol. II, pp. 363-390. 
-en última instancia la de la nacionalidad- pueden caracterizarse como identidades, pero la identidad consiste, principalmente, en ser miembro de un grupo y los individuos en tal caso se llaman "miembros".

En tercer lugar, es necesario enfatizar que toda operación que se emprende, tal como la escritura de una carta, tiene lugar sobre el trasfondo de lo que es habitualmente aceptado por los individuos y tradicionalmente aceptado por los grupos, en los que -hablando en general- "aceptado" incluye el ser querido de un cierto modo automático o rutinario, usualmente no advertido o inconsciente, que puede llamarse "uso".

El caso de Taiwan, ampliado espacial y temporalmente, puede ilustrar esta ampliación de la explicación de Gurwitsch. Haciendo abstracción, provisionalmente, de los usos, valores y cosas por el estilo, y considerándolo como una cosa naturalista experienciada no reflexivamente, Taiwan es una isla con forma de batata que tiene 90 millas de ancho y 245 millas de longitud (o sea, 394 x $144 \mathrm{~km}$.), con una superficie de 13.900 millas cuadradas (unos $36.188 \mathrm{~km}^{2}$ ), es decir, la mitad del área de Irlanda. Se encuentra a unas 100 millas (unos 160 km.) costa afuera de China, entre Hong Kong y Shangai; al norte tiene al Japón y, al sur, Filipinas. La isla posee montañas en la zona este, así como valles fértiles y llanuras en el oeste. Existen 1.500 especies de plantas autóctonas, muchas especies de aves y, también, osos, jabalíes, ciervos, zorros voladores, etc., pero no hay tigres; el ciervo autóctono Sika se halla hoy extinguido. Describiremos en un momento su población. El clima es subtropical como el del sur de Florida. Llueve al menos 200 pulgadas al año (unos 5.000 milímetros), las temperaturas oscilan entre $90^{\circ} \mathrm{F}$ en verano y $59^{\circ} \mathrm{F}$ en invierno (entre $33^{\circ} \mathrm{y}$ $15^{\circ} \mathrm{C}$ ), hay tifones $\mathrm{y}$, debido a que se encuentra al borde de una placa tectónica, hay terremotos.

De esta manera, Taiwan puede ser considerada del mismo modo en que se puede examinar un tintero, no en el sentido de un objeto de uso, sino como un sólido hueco de forma predominantemente cilíndrica y de ciertas dimensiones, que contiene un fluido azul y que se halla situado, junto a un rectángulo blanco de tal y tal largo y ancho, sobre una base plana rectangular de color marrón. Esto describe el campo temático de la escritura de cartas cuando se ha hecho abstracción de los usos y de los objetos de uso. Sin embargo, mientras que una persona puede tener experiencia de un escritorio con una simple mirada, el clima, la ecología, la geografía y la geología de una dilatada isla sólo pueden 
comprenderse relacionando muchas observaciones, algunas hechas mediante satélites, en un modelo conceptual obtenido mediante el pensamiento.

Si se relaja esta abstracción de modo que podamos pensar acerca de las cosas mencionadas tal como se las encuentra originalmente en una variedad de actitudes prácticas y si, con respecto a las cosas-en-cuanto-encontradas y a los encuentros de ellas por parte de los taiwaneses, distinguimos también una cantidad considerable de su pasado, puede advertirse que el estrecho de Taiwan entre la isla y el continente es algo que ha tenido un uso. Es ancho y bastante turbulento y, en virtud de ello, dificultoso de cruzar antes de que naves relativamente modernas como las portuguesas navegaran en sus aguas cuando arribaron y le pusieron nombre a la "Ilha Formosa" (Isla Hermosa). Excepto por un breve período anterior a 1886, cuando comenzó la colonización china seria ${ }^{11}$, el estrecho funcionó como una barrera - un foso natural, podría decirse- contra las invasiones organizadas desde el continente y por siglos fue una barrera más efectiva que la Gran Muralla. Pero la función del estrecho como barrera contra las invasiones no impidió la pesca, el comercio (y los piratas), ni que fuera un corredor migratorio durante milenios. Se pueden decir cosas similares con respecto a la caza y al cultivo de la tierra, en donde el sacar ventaja del potencial ecológico es asimismo una cuestión de usos y de cosas-en-cuanto-usadas, en virtud de lo cual el medio ambiente es, de un modo muy básico, algo cultural ${ }^{12}$.

${ }^{11}$ De 1683 a 1886 Taiwan fue una zona de frontera. La mayor parte de ese tiempo, los dominadores Qing se opusieron a la inmigración china e igualmente a los mercaderes y misionarios europeos. Entre 1826 y 1835, Taiwan fue incorporada al imperio y algunos oficiales activistas la vieron como una salida para los pueblos económicamente deprimidos en el sudoeste de China, capaz de exportar arroz, azúcar y té y esperaron establecer allí cimientos para una civilización china. "Dichos cimientos incluyen a las familias fuertes, dominadas por los varones, las cuales, idealmente, albergan varias generaciones bajo un mismo techo o, al menos, en un entorno común; una economía agrícola productiva, que crece en el rubro de los granos; una actividad comercial próspera financiada por los fondos excedentes de las familias granjeras; la propiedad controlada, regulada y explotada por el Estado; el desarrollo de una clase social burocrático-escolarizada que podría, a su vez, ser ejemplo para el resto de la sociedad en las virtudes propiamente confucionistas, humanitarias, relativas al modo de tratar a las demás personas; y el complejo chino de religiones, que combina elementos del budismo, el taoísmo, la propiciación de los antepasados y una variedad de dioses al servicio práctico de los orantes". CCT, p. 10.

12 Lester Embree, "The Constitution of Basic Culture". Traducido al esloveno en Phainomena, vol. 10 (2001) pp. 47-60; traducido al japonés por Tatsuhiko Sakurai como "Kihon-teki Bunka no Kousei", en Bunku to Shakai [Cultura y sociedad], Tokio, 2002, vol. 3, pp. 75-92; traducido al checo como "Konstituce zakladni kultury", en Ivan Blecha (ed.), Fenomenologie $v$ pohybu, 2003, pp. 35-44; traducido al castellano como "La constitución de la cultura básica", en César Moreno Márquez / Alicia María de Mingo Rodríguez (eds.), Signo. Intencionalidad. Verdad. Estudios de fenomenologia, Sevilla, S.E.F.E. / Universidad de Sevilla, 2005, pp. 345-355. 


\section{LA POBLACIÓN DE TAIWAN}

Los grupos que sucesivamente arribaron a la isla arrojan luz sobre quiénes usaron aspectos de ella de variadas maneras. Nuestros medios de comprensión son aquí la arqueología, la economía, la historia y la lingüística, que son ciencias culturales, mientras que se puede decir que la sección anterior se basaba en la ciencia naturalista. Hubo cazadores y recolectores durante 30.000 años, pero los pueblos austronesios comenzaron a llegar hacia el 4.000 a. C., e introdujeron la caña de azúcar, el arroz, la malanga, el té, así como las batatas, y también gallinas, perros, cerdos, búfalos de agua y bueyes. Las herramientas de hierro aparecieron hace unos 2.000 años. Se desarrollaron poblaciones independientes en las que los varones cazaban y pescaban mientras las mujeres cultivaban y recolectaban. Un colega informa que hoy en día sobreviven nueve grupos y trece subgrupos, a los que se suma un décimo cuarto que busca reconocimiento oficial. Comprenden el $2 \%$ de la población actual. El nombre "Taiwan" parece provenir del Sirayan, una lengua aborigen.

Los grupos chinos han llegaron más recientemente. Los Hakka comenzaron a inmigrar durante la dinastía Tang, pero la mayoría llegó entre los siglos XVI y XVIII y hubo algún entrecruzamiento de sangre con los aborígenes. Durante el mismo período arribó gente de la provincia de Fujian, que hablaban Minnan, hoy Ilamado también "taiwanés". Los pobladores que no son Hakka Han son llamados colectivamente "Hoklo". Hoy continúan existiendo diferencias de lenguaje, así como sigue la lucha por el reconocimiento de las minorías, reprimidas en su momento por Chian Kai-shek ${ }^{13}$.

\footnotetext{
13 "Puesto que la población china de Taiwan manifiesta características que identifican en común a un grupo étnico, el Hakka, puede considerarse a los fujianeses Quanzhou y a los fujianeses Zhangzhou como subetnias. Los Hakka emigraron a Taiwan desde las regiones fronterizas entre Guangdong y Fujian, mientras que la población fujianesa provino predominantemente de Zhanghou y Quanzhou en el sur de la provincia Fujian. Los Hakka hablan un dialecto (dejando de lado la cuestión política que implica definir una lengua como dialecto y otra como lengua oficial o mandarín, mas, para hacer las cosas aún más complicadas, ipodemos encontrar en Taiwan cinco diferentes Hakka! De ellos, uno es casi una mezcla de Hakka y Hoklo), que resulta incomprensible para el Minnan, la lengua de los fujianeses y, recíprocamente; evidencian, además, ciertas características culturales tales como una relativa independencia que gozan las mujeres (que no se vendaban los pies y trabajaban en los campos agrícolas), una mayor tendencia a diversificar las economías familiares sobre una base más agraria que mercantil, el uso de sombreros de ala ancha y otros atavíos distintivos y la adoración de ciertos dioses, así como ciertos rituales particulares de su propia subetnia. Los dos grupos fujianeses hablan un dialecto común, pero sus acentos son distintivos; ellos también evidencian diferencias en las deidades y rituales a los que son afectos. En el Taiwan de los siglos dieciocho y diecinueve, los conflictos entre las poblaciones de las regiones Hakka y fujianesa podían llegar a ser violentos. En ausencia de tales conflictos, a menudo se magnificaban las tensiones entre las subetnias Zhangzhou y Quanzhou, lo que acarreaba disputas tan violentas como las manifestadas por la rivalidad entre los Hakka y los fujianeses. Del lado más positivo de estas rivalidades, el orgullo subétnico condujo al auxilio mutuo, a realizar proyectos en cooperación y
} 
De 1626 a 1641 los españoles dominaron parte de la isla. Los holandeses colonizaron Taiwan más extensamente en 1624, lo usaron como base para el comercio e importaron fuerza de trabajo de Penghu y también de Fujian. Chen Ch'en-kung, quien defendió a los Ming contra los Manchú, expulsó a los holandeses en 1662. Se produjo una retirada a Taiwan después de que los Ming cayeron ante los Manchú y comenzó la dinastía Qing. Taiwan fue anexado en 1683, si bien la isla continuó durante dos siglos más siendo "un área fronteriza bastante salvaje y confusa"14. La Guerra del Opio de 1839 a 1842 abrió puertos taiwaneses a los europeos y entonces, tras vencer en la primera guerra chinojaponesa, los japoneses colonizaron la isla intensivamente a partir de 1895. Introdujeron la educación universal en japonés y los isleños alfabetizados antes de 1945 pueden todavía hoy preferir dicha lengua; todavía hay elementos de japonés en el taiwanés, pero la inmigración ha sido escasa durante las últimas décadas. Los taiwaneses fueron considerados súbditos del emperador japonés, algunos sirvieron en el ejército japonés durante la segunda guerra mundial, y los norteamericanos bombardearon extensamente Taiwan ${ }^{15}$.

La Declaración de Potsdam de 1945 restituyó Taiwan a la República de China de Chian Kai-shek, el autoritario sucesor de SUN Yat-sen, cuya república había reemplazado a los Qing en 1912. EL período de guerra civil comenzó en el continente en 1916. El Partido Comunista Chino se estableció en 1921. Como consecuencia de la derrota japonesa en 1945, Chiang perdió la guerra civil frente a Mao Tse-tung y un millón trescientos mil miembros de su partido Guomindang tuvieron que refugiarse en Taiwan en 1949. Conocidos también como Nacionalistas, este cuarto grupo Han se estableció principalmente en el norte, alrededor de la capital, y conforma el $12 \%$ de la población total. Su en ocasiones

\footnotetext{
a la celebración de acontecimientos religiosos a los que eran incorporados miembros subétnicos ajenos a la aldea". CCT, p. 206.

${ }^{14}$ Ibidem, p. 10.

15 "Los japoneses fueron artífices de la industrialización de la isla; extendieron los ferrocarriles y otras redes de transporte, construyeron un extenso sistema sanitario y revisaron el sistema de la escuela pública. Durante este período, se incrementaron significativamente las producciones de arroz y de caña de azúcar. En un cierto momento, Taiwan llegó a ser el séptimo mayor productor de azúcar en el mundo. Con todo, los aborígenes de las etnias chinas y taiwanesas fueron clasificados como ciudadanos de segunda y tercera clase. La violencia en gran escala continuó durante la primera década de dominio. Japón fletó más de 160 barcos de guerra para destruir las tribus aborígenes de Taiwan en los cincuenta y un años que duró su dominación colonial sobre la isla... Hacia 1935, los japoneses comenzaron a poner en práctica en toda la isla un proyecto de asimilación destinado a vincularla más firmemente al Imperio Japonés. El plan funcionó muy bien; a tal punto que decenas de miles de taiwaneses se unieron a las filas del ejército japonés y lucharon lealmente por él. Por ejemplo, el hermano mayor del ex-presidente de la ROC Lee Teng-hui, sirvió en la marina japonesa y murió en cumplimiento del deber en las Filipinas en febrero de 1945". (http://en.wikipedia.org/wiki/Taiwan; consultada el 1/28/08).
} 
violento gobierno militar, que duró 50 años, impuso el mandarín en las escuelas, el gobierno y los medios de comunicación, en lugar del japonés ${ }^{16}$.

Los diferentes puntos de vista étnicos típicos de Taiwan todavía me resultan poco claros. Ha existido, sin embargo, una oposición política entre los grupos "azules" y hablantes del mandarín, en el norte, y el resto de los taiwaneses, que son "verdes", especialmente en cuanto a las relaciones con la "Gran China", como he oído llamarla, así como a la pertenencia a las Naciones Unidas, pero no me queda claro si no se trata de una simplificación excesiva; e incluso algunos colegas me dicen que es algo cada vez menos válido.

La mayoría de las sociedades en la historia es o ha sido, formal o informalmente, una colonia dentro de un imperio $y$, de ese modo, ha participado de civilizaciones mayores. Después de los holandeses, Taiwan estuvo bajo la dominación de los Qing, de los japoneses y del Guomindang, en cada uno de los casos durante unos cincuenta años, y ahora es una provincia de la República Popular China. Una cuestión interesante es la de si la influencia norteamericana tiene carácter imperial. El inglés está ampliamente difundido como segunda lengua y el hijo de un amigo mío norteamericano dirige una cadena de Pizza Hut en la isla. Si bien estos contextos más amplios merecen una mención, de todos modos nuestro interés aquí se centra en la cultura interna de Taiwan.

\section{RELIGIÓN Y PENSAMIENTO}

Lo dicho hasta ahora se basa principalmente en el primer capítulo del libro Culture and Customs of Taiwan. El segundo capítulo trata acerca de la religión y el pensamiento, y merece atención aunque no sea más que para mostrar que este modelo de la cultura de una sociedad-en-cuanto-encontrada y en la que participan diversos grupos incluye la creencia o componente cognitivo. De ahí que el énfasis en este trabajo se desvíe ahora del examen del uso o el querer tradicionales -colectivos y típicamente inconscientes en la significación amplia-

\footnotetext{
16 "Muchos chinos por todo el mundo han reconocido desde entonces el mandarín como la lengua común de comunicación. Los taiwaneses en general no parecen tener grandes problemas con este papel que cumple el mandarín, pero hoy [en 1998] existe una puja para asignarle al Minnan un papel mayor, ya que su empleo a fines del siglo veinte se halla más extendido en la televisión, en la radio y en las reuniones públicas de lo que era políticamente posible durante la década de 1980 . Hay en general un interés creciente por estas cosas que son específicamente taiwanesas en lo cultural". CCT, p. 24.
} 
y se dirija al examen del encuentro colectivo -a menudo más consciente de sí-, en el que predominan la creencia y las cosas-en-cuanto-creídas. Estos problemas cognitivos han estado en el centro de atención de la fenomenología constitutiva, comenzando por el propio Husserl, pero sin que se pusiera el énfasis -incluso en el caso de Schutz- en los grupos, la tradición y la cultura, tal como se hace aquí.

En lo que respecta a la religión:

La cultura religiosa de Taiwan refleja una condición única por tratarse de una cultura aportada por inmigrantes de Fujian y Guangdong, influida por la presencia japonesa y occidental, y luego controlada por el partido Guomindang desde 1947. Las actividades religiosas predominantes son los rituales ancestrales y los festivales comunitarios del templo. De acuerdo con las estadísticas del ROC hechas en 1994, 11,2 millones de los 21 millones de habitantes de Taiwan se consideran a sí mismos personas religiosas. De estos taiwaneses religiosos, hay 43 por ciento de budistas, 34 por ciento de taoístas, 8 por ciento de yiguando, 6 por ciento de cristianos y 9 por ciento de seguidores de otras religiones. Estas estadísticas no retratan de manera adecuada la rica diversidad de rituales, sectas, templos y deidades religiosas que son parte de la vida taiwanesa. Por lo demás, la incesante vitalidad de la religión popular taiwanesa y la reverencia a los antepasados hacen que la distinción entre budistas y taoístas sea más bien una cuestión de preferencias en la designación que de práctica real. ${ }^{17}$

En Taiwan sigue teniendo importancia el pensamiento tradicional en torno al Tian o cielo y el Dao o camino ${ }^{18}$. Hay también bastante confucianismo ${ }^{19}$. Y

\footnotetext{
${ }^{17}$ Ibidem, p. 31.

18 "De acuerdo con la concepción china de un orden natural armónico, todas las cosas del cielo y de la tierra están vinculadas por la fuerza de la vida, qi. Qi es el aliento del universo y, en los seres humanos, el aliento de vida. El fluir de qi y los patrones de cambio se comprenden en términos de dos opuestos polares: yin y yang. Yin y Yang son opuestos polares que se advierten en las transformaciones y en las relaciones de todas las cosas. Lo frío y lo cálido, lo masculino y lo femenino, lo seco y lo húmedo, la luna y el sol, la noche y el día, son todos ejemplos de la dicotomía yin-yang. Otro concepto chino que interpreta las relaciones entre las cosas y el cambio es el de los cinco agentes: madera, fuego, tierra, metal y agua. Estos conceptos tradicionales $-q i$, los cinco agentes y la polaridad yin-yang- se emplean para conceptualizar y organizar todos los aspectos de la naturaleza y la sociedad. Las estaciones del año se pueden comprender en términos del flujo y reflujo de yin y yang y de la dominación alternada de los cinco agentes. El cambio histórico puede verse como el movimiento de los cinco agentes triunfando unos sobre otros. Todavía más significativo es el hecho de que el ser humano es un microcosmos del universo natural. Como el resto del universo, la vida humana está gobernada por qi, los cinco agentes y la polaridad yin-yang. Los órganos principales del cuerpo están dominados por los cinco agentes; las fuerzas del yin y el yang se encuentran equilibradas en un cuerpo sano". Ibidem, p. 32.

19 "Buena parte de la filosofía de Confucio concuerda con la tradición popular y con la religión organizada de Taiwan. El ideal confuciano de la piedad filial, por ejemplo, se expresa ritualmente en los funerales taiwaneses, en los santuarios ancestrales y en los festivales religiosos. La tradición confuciana es asimismo estrictamente jerárquica, en razón de que enfatiza las obligaciones en una sociedad ordenada jerárquicamente y centrada en los vínculos de padre e hijo, hermano mayor y menor, esposo y esposa, ancianos y jóvenes y soberanos y súbditos. Las tendencias autoritarias y patriarcales de estas relaciones se están poniendo en cuestión de manera creciente por parte de los taiwaneses más igualitarios y con mentalidad democrática". Ibidem, p. 34.
} 
una sección de Cultures and Customs of Taiwan está dedicada a "Alimento y bebida como medicinas" ${ }^{20}$.

Pero, por otro lado, parece que, al menos en los grupos educados, hay un predominio de la "visión científica moderna"21. Hoy en día se ha extendido el estudio y la enseñanza no solamente de la ciencia y la tecnología occidentales, sino también de la filosofía occidental, incluyendo a Kant y a Hegel, al existencialismo y, como puedo atestiguar, a la fenomenología; hay incluso algo de filosofía medioambiental y de feminismo. Dado el foco que tiene la economía en la alta tecnología, no es sorprendente el considerable desarrollo de la filosofía de la ciencia y la tecnología naturalistas, pero yo he conocido también psicoterapeutas científico-culturales y hasta una docena de enfermeras fenomenológicas.

Esto es suficiente con respecto a las actitudes de creencia en la significación amplia.

\section{CULTURA SUPERIOR}

Los capítulos centrales de Culture and Customs of Taiwan se refieren a un tercer tipo de actitud que llamo valorativa en amplio sentido. Puede decirse que se refieren a la llamada "cultura superior" e incluso a la estética. En estos capítulos se cuentan cosas fascinantes acerca de la arquitectura, la cocina, la danza, los entretenimientos, los festivales, la moda, las películas (Crouching Tiger Hidden Dragon fue dirigida por un taiwanés, Ang Lee), la literatura, la ópera, la música y las artes visuales (incluyendo la caligrafía). Es posible que esta mitad del libro esté puesta ahí especialmente para los forasteros, pero también queda claro que se trata de cosas que los taiwaneses mismos, de diferentes maneras, valoran profundamente. Agrado y desagrado son los modos positivo y negativo de valoración y en la vida cotidiana no requieren de autoconciencia, ni mucho menos de análisis. El componente valorativo en los encuentros y los valores de

${ }^{20}$ Por ejemplo: "La medicina nutricional taiwanesa incluye una categoría de alimentos conocida como bu -'suplemento', 'parche' o 'fortalecedor'- estrechamente asociado con ciertos platos calientes, aunque distinto de las polaridades humorales de cálido-frío, seco-húmedo. Se cree que los alimentos bu son efectivos en particular para estimular la reparación de los tejidos, para reestablecer la circulación sanguínea y que poseen una función tónica general. Los alimentos considerados bu se digieren en general con facilidad y poseen proteínas de alta calidad; por tanto, esta categoría ha sido deducida, en lo fundamental, a partir de bases racionales" (Ibidem, p. 153). Con todo, algunos alimentos bu se reconocen de maneras menos occidentales, como las nueces por la semejanza de su forma con la del cerebro.

${ }^{21}$ Ibidem, p. 32. 
las cosas-en-cuanto-encontradas están en analogía con lo que son los usos de las cosas para el componente volitivo. Los objetos de valor, incluyendo los objetos de disfrute, son una especie del género objeto cultural y situaciones estéticas tales como las bodas son algo que en Taiwan se disfruta mucho. Hay, desde luego, muchas otras cosas que tienen una valoración muy alta, como, por ejemplo, la familia.

\section{SOCIEDAD Y ECONOMÍA}

Me ocuparé ahora de las etapas de la vida, del parentesco, del género y del modo en que está cambiando actualmente la cultura en la sociedad taiwanesa por influencia de la economía. Los dos últimos capítulos de Culture and Customs of Taiwan son aquí mi fuente.

En Taiwan, los niños tienen pocas responsabilidades antes de los seis años, pero están presentes en las actividades de la familia, tanto económicas como de otros tipos. Puede que los varones tengan que cuidar a los animales de tiro, que todavía se emplean a pesar del extendido uso de pequeños tractores, sin embargo es preciso que no se malentienda la situación.

Sin duda hay algo de sentimentalismo en el hecho de mantener un buey o un búfalo de agua en esta época, y el apego emocional que los niños tienen por los animales parece ser universal, pero no se alienta semejante afición en los niños taiwaneses. Se respeta a los animales por sus funciones económicas, utilitarias, no por su atractivo como mascotas. $^{22}$

El género, desde luego, se inculca desde el comienzo. Tradicionalmente a las niñas se les enseñaban habilidades domésticas para su futuro en las familias de los varones con quienes se casaran ${ }^{23}$. Los varones, en especial los primogé-

22 Ibidem, p. 192.

23 "La niña aprende que el hogar donde aprendió a gatear y a caminar no es a la larga el lugar que alberga su familia más importante, no es la familia de su destino, no si cumple con su deber y se casa temprano y del modo apropiado, sin importar lo ligada que esté emocionalmente a la familia de su nacimiento. Aprende que su familia se ocupará de ella y que le exigirá trabajos productivos mientras permanezca en el grupo familiar, pero también que sus posibilidades en el mundo manifiesto y en la eternidad dependen de que acepte o se asegure una buena pareja matrimonial. Si permanece en su hogar demasiado tiempo, se convertirá en una carga para su familia; y si llega a la edad de dieciocho, diecinueve o veinte años sin buenas perspectivas de matrimonio, tendrá que considerar la naturaleza de dicha carga y cooperar haciendo esfuerzos más persistentes para aliviarla gracias a la obtención de un marido. Se llevará con ella una dote que, en general, es concedida por los padres, es esperada por la familia de su pareja y posee, dentro de las posibilidades económicas de su familia natal, un valor monetario significativo. Conservará el control sobre dicha dote en su matrimonio, cultivará la lealtad emocional de sus hijos 
nitos, aprenden que ellos son altamente valorados en lo que, desde luego, es un patriarcado ${ }^{24}$. La educación gratuita para chicas y muchachos es obligatoria y competitiva. Un examen al final del primer ciclo de enseñanza media abre tres caminos: uno hacia la secundaria académica, otro hacia la escuela técnica de tres años en campos tales como la carpintería y la contabilidad, y un tercero para llegar a ser un técnico altamente entrenado. A su vez, si aprueban los exámenes pertinentes, los estudiantes pueden continuar con las carreras universitarias de grado y doctorado en campos tales como la arquitectura, la ingeniería y la tecnología en computadoras.

Conseguir la admisión en una secundaria académica, sin embargo, es el camino más seguro para alcanzar el mayor nivel de prestigio social y hace posible un temprano ingreso en las mejores instituciones universitarias [...] La universidad más prestigiosa en todo Taiwan es la Universidad Nacional de Taiwan, donde un desempeño excelente y vinculaciones bien establecidas aseguran casi con certeza el triunfo de una persona en ámbitos tales como la medicina, el derecho, la economía o los asuntos académicos, o bien aumentan las probabilidades de conseguir un lugar como investigador asociado en la Academic Sinica o bien un empleo importante en la burocracia gubernamental. ${ }^{25}$

La etapa de la vida cambiaba, tradicionalmente, con el matrimonio. Uno es un muchacho hasta que se casa. Siguiendo la tradición, los matrimonios eran arreglados por las familias y probablemente no se contemplaba mucho enamoramiento previo.

Las costumbres matrimoniales taiwanesas dictaminan que la novia y el novio no sólo tienen que tener apellidos diferentes sino también que deben provenir de aldeas dife-

de la misma manera que ve a su madre construir su propia 'familia uterina' como un bastión dentro del reino patriarcal, y procurará aumentar los derechos y los intereses de su unidad conyugal dentro de la familia numerosa". Ibidem, p. 194.

24 "En la familia taiwanesa, el varón percibe en los tonos de voz y en el afecto físico que muestran sus parientes el mensaje de que su nacimiento ha sido algo especial, particularmente si se trata del primer hijo varón, quien, suponiendo el requisito de su longevidad, podría asegurar la continuidad de la línea masculina y ser el consuelo de sus padres en su vejez. Con el tiempo aprende que no sólo es bienvenido sino que se espera que permanezca, ya sea física o económicamente, próximo a los parientes de su línea paterna. Se entera de que, independientemente del orden de nacimiento, tendrá su parte en la propiedad del padre, mancomunada con las partes de sus hermanos mientras se pueda sostener el ideal fraternal, pero luego dividida cuando las unidades conyugales comiencen a presionar por la independencia. El muchacho aprende que en el futuro tendrá una obligación esencialmente religiosa de hallar una habilidad económica productiva que haga expandir la fortuna familiar, que logre que las generaciones venideras sean más prósperas, y que con la mayor riqueza posibilite realizar sacrificios más suntuosos a los antepasados, haciendo mayor justicia a su bienestar material en el reino allende este mundo". Ibidem, p. 194; cfr. p. 167.

${ }^{25}$ Ibidem, p. 198. "La educación es en Taiwan de alta calidad, centrada en el profesor y basada en los exámenes. Se imparte en un estilo que hoy se considera incompatible con las necesidades y demandas de los estudiantes en los Estados Unidos. En Taiwan, los estudiantes se ponen de pie cuando entra el profesor y saludan a su instructor con un gesto verbal de reverencia. El profesor habla. Los estudiantes escuchan y toman notas. El sistema es muy eficiente y produce estudiantes que poseen un enorme reservorio de hechos y figuras. El sistema no está diseñado para producir estudiantes altamente creativos, originales y con pensamiento libre, sino que produce estudiantes que poseen un cuerpo considerable de conocimientos en historia, geografía, matemática y ciencias". Ibidem, 194. 
rentes. En el caso ideal, los dos jóvenes a ser unidos tienen poca familiaridad el uno con el otro; partes importantes del ritual matrimonial suponen que la novia y el novio se ven por primera vez allí. ${ }^{26}$

Abundantes rituales tanto en los preparativos como en la ceremonia misma de la boda, son algo que las familias disfrutan, si bien algunos colegas me informan que estos ideales han decaído en las últimas décadas.

Cuando se transmite la autoridad del viejo patriarca en la última etapa de su vida, se le concede respeto formal y se lo sostiene, pero no se lo ama, como sí ocurre con su esposa ${ }^{27}$. Los miembros en las etapas de la vida que se acaban de describir tienen valores y usos correlativos a una valoración y a un querer habituales - usualmente, no autoconscientes- por parte de los diversos miembros de la familia, tanto, masculinos como femeninos, tanto adultos como niños.

La familia parece haber sido para los taiwaneses algo tan central como lo es la individualidad para la cultura norteamericana. Tradicionalmente, las familias nucleares han sido algo inusual, pero los colegas me informan que hoy en día unos dos tercios son nucleares. Además, siguiendo la tradición,

la familia troncal, que incluye un hijo casado y su familia, así como su unidad familiar, junto con su madre, padre y hermanos solteros; y la familia "numerosa", que consiste en al menos dos hijos casados y sus unidades familiares viviendo con su madre, padre, hermanos no casados y cualquier otro pariente asociado al mismo hogar. Las dos formas de familia fueron por mucho tiempo idealizadas en la sociedad taiwanesa. En Taiwan, como en otras sociedades chinas, el ideal cultural es la familia numerosa, cuya meta última consiste en "cinco generaciones bajo un mismo techo". ${ }^{28}$

Los ideales se relacionan, desde luego, con valores. Merece atención también el hecho de que, "en sus aspectos económicos, una familia es una pequeña corporación, que extiende sus empresas en tantas áreas diferentes como le es posible"29. Se trata, nuevamente, de cuestiones con valores y usos para los taiwaneses.

${ }^{26}$ Ibidem, p. 168.

27 "Los taiwaneses de mayor edad con frecuencia enfrentan un destino desagradable, aunque seguro. Tras haber cultivado una posición de gran importancia en el grupo jail tanto tiempo como les fue posible, finalmente se encuentran en la situación de tener que ceder el liderazgo a los hijos, que les dispensan un grado de respeto formal, pero con toda probabilidad tienen muy poco afecto natural por ellos. Las madres de mayor edad, por el contrario, a menudo tienen un destino más agradable. La joven madre plantó las semillas del afecto cuando atrajo hacia sí su familia uterina. Como mujer mayor, puede coser y remendar la ropa, así como tener en brazos a los niños pequeños. La esposa, jefa ahora de su propio reino doméstico, se halla en una disposición más favorable para con su suegra". Ibidem, p. 177.

${ }^{28}$ Ibidem, p. 171.

${ }^{29}$ Ibidem, p. 203. 
Más allá de la familia se encuentran la aldea, el linaje y el clan. Las aldeas necesitan de la cooperación para las tareas que reportan beneficio mutuo, tales como la construcción de obras de irrigación ${ }^{30}$. Los linajes se forman cuando un número de grandes unidades familiares funda una finca en honor de un antepasado del cual descienden; un antepasado que ha traído gran honra a sus parientes mediante el éxito en los negocios, la obtención de una posición alta en el gobierno, etc., y que ha legado una cuantiosa herencia parte de la cual podría dotar al linaje y beneficiar a sus miembros masculinos ${ }^{31}$. Los clanes incluyen gente del mismo apellido; las líneas de descendencia no requieren de prueba estricta, pero todavía se emplean términos relativos al parentesco, lo que es otra indicación del valor atribuido a las relaciones familiares ${ }^{32}$.

Más extensos que los linajes y los clanes son los grupos étnicos mencionados más arriba. Los grupos que les siguen en magnitud son los partidos políticos. No me resulta claro hasta qué punto tienen estos un carácter familiar, pero todo lo demás sí lo tiene. En todo caso, tales grupos no seguirían existiendo -al igual que, por ejemplo, habrían desaparecido las diferencias lingüísticas- si no fueran claramente valorados y queridos o usados de maneras tradicionales y a menudo inconscientes.

Por último, el grupo más alto es la nación.

Hoy se ha incrementado en gran medida la identificación amplia de la isla. En los últimos cincuenta años, la expansión de los sistemas de transporte y comunicación, así como el aumento de la interconexión económica, han servido para incrementar la identificación amplia de la isla y el advenimiento de una democracia política genuina ha

\footnotetext{
30 "La lealtad a la aldea ha sido en general un hecho observable en la organización comunitaria en Taiwan; las circunstancias prevalecientes pueden reforzar o debilitar su lealtad. Tradicionalmente, la lealtad hacia toda la aldea y su identificación con ella han tenido su fuerza mayor, que se advierte análogamente en la filiación del linaje, cuando los habitantes enfrentaban con regularidad peligros físicos ante grupos externos a la aldea, o bien cuando las exigencias de la economía agrícola le otorgaban valor especial a la cooperación en la familia, el linaje o el apellido". Ibidem, p. 206.

31 "Con los ingresos generados por el Estado, los líderes del linaje podían invertir en tierras y empresas, de los cuales todos los miembros masculinos del linaje obtenían beneficios. Las ganancias generadas por el Estado podían emplearse para fundar escuelas, financiar esfuerzos de ayuda a favor del linaje y de la comunidad en tiempos de desastre natural, establecer milicias locales con el fin de proveer seguridad física a los miembros del linaje, proporcionar servicios de asistencia social para los miembros pobres del linaje o para costear necesidades especiales, y llevar a cabo pródigos rituales y conceder generosas fiestas en honor de los antepasados. Al tener mayor capacidad de dotar la propiedad del linaje, las familias de abundantes recursos tenían mayores probabilidades de formar linajes que las familias de medios pobres o moderados. La gente relativamente más humilde, sin embargo, podía formar organizaciones de linaje. Mediante estas vinculaciones fuertemente rituales, podían asegurarse redes destinadas al progreso común y, en especial, se proveía seguridad en áreas desguarecidas del imperio de la ley y de los esfuerzos de protección del gobierno". Ibidem, p. 178.

${ }^{32}$ Ibidem, p. 179.
} 
acrecentado el interés que la mayoría de la gente siente que puede tener en la vida de la nación entera. ${ }^{33}$

El imperio, al que aludimos antes, se hallaría aún más arriba, pero se encuentra más allá de la nacionalidad, cuya clarificación intento abordar en estos momentos. Hay muchos otros aspectos que deben ser descritos en términos de valores y usos y, en realidad, de sistemas completos de aquellos, a fin de comprender las culturas de familias, linajes, etnicidades, partidos y de la nación, pero, como ya he dicho, aquí se trata tan sólo de un comienzo.

\section{INFLUENCIAS ECONÓMICAS RECIENTES}

Las dos últimas secciones del libro de Davidson y Reed, Culture and Customs of Taiwan, están consagradas al "impacto de la economía cambiante sobre los valores de la familia" y "los valores de la comunidad". En las últimas décadas, Taiwan se ha convertido en uno de los cuatro "tigres asiáticos" en la economía mundial, y esta circunstancia ha afectado a su cultura.

Hasta hace poco, las familias numerosas compartían sus casas en aldeas agrícolas, pero a partir más o menos de 1950 se ha producido una veloz industrialización y urbanización. Esto ocurre con el dominio del gobierno militar del partido Guomindang, durante medio siglo basándose en los cimientos japoneses establecidos en el anterior medio siglo. A mediados de la década de 1980, sólo el $16 \%$ de la fuerza laboral se hallaba aún en la agricultura y estaba representada en su mayoría por mujeres y ancianos. Las granjas familiares fueron limitadas por ley a 2,5 acres (11 hectáreas) entre 1949 y 1953, las cultivadoras movidas a motor reemplazaron a la mayor parte de los bueyes y se generalizó el uso de fertilizantes y pesticidas químicos. Al arroz, el azúcar y la piña como cultivos para exportación se añadieron champiñones y espárragos.

Taiwan tiene pocos recursos del tipo de minerales, metales y combustible fósil (excepto carbón), pero, en cambio, sí tiene una fuerza de trabajo disciplinada. Los productos textiles primero, y después el montaje de aparatos electrónicos, han tenido un carácter central (durante mi último viaje supe que se tenía la esperanza de que el nuevo I-Phone de Apple se fabricara allí, como

${ }^{33}$ Ibidem, p. 208. 
así ha sido, en efecto). La industria norteamericana fue bienvenida después de 1968, la industrialización continuó al ritmo más veloz de la Tierra y el crecimiento del sector de comercio de servicios lo hizo aún más rápidamente. Las condiciones en las fábricas durante la década de 1970 eran apenas un poco mejores de las que Dickens describía en su época. Asimismo, también me dijeron que en la actualidad la economía de Taiwan está tambaleándose debido a que el capital se está trasladando al continente, en donde la mano de obra es más barata.

Sin duda, se ha tratado de una "industrialización descentralizada", en la cual la presión de la familia y la granja ha sido poderosa y ha frenado el ritmo de urbanización. Pero el hecho es que las familias sobresalen en la ciudad.

La mayoría de estos negocios familiares se hacía en pequeña escala $y$, cuando otros sectores eclipsaron a la agricultura, estos pequeños negocios se encontraron al frente de la transformación económica de Taiwan. Sin embargo, a la vez que estas pequeñas empresas resultaron ser la columna vertebral de la modernización económica, algunas familias inevitablemente advirtieron su potencial corporativo: el ideal de la familia numerosa contribuyó poderosamente tanto al crecimiento de las pequeñas iniciativas como al de los negocios corporativos en la economía taiwanesa. ${ }^{34}$

Las grandes ciudades crecieron mediante una inmigración en cadena -el padre o el hijo mayor se marchaban primero a las ciudades y luego traían a los restantes miembros de la familia-; con todo, el 85\% de los habitantes actuales de las ciudades regresa a su aldea para celebrar el Año Nuevo. También en otros aspectos los procesos y productos de la economía han dependido de valoraciones y voliciones en la significación amplia, que son tradicionales, colectivos $y$, en el mejor de los casos, semiconscientes.

La familia numerosa, los linajes y los clanes siguen existiendo porque se adaptan. La cohabitación y el compartir las comidas no parecen ahora necesarios a fin de mantener la forma de la familia nuclear. De manera creciente, tanto el padre como la madre trabajan fuera del hogar y la tasa de natalidad ha descendido. Las "camarillas" masculinas son mucho más poderosas que en Occidente. Con todo, las mujeres han buscado la igualdad con respecto al varón en temas tales como el divorcio y la herencia; desde comienzos de los años 70, se han modificado las leyes e incluso se han implementado algunas nuevas. Ellas han aprovechado sus oportunidades educativas. Es frecuente hoy en día

${ }^{34}$ Ibidem, p. 205. 
que las hijas solteras trabajen fuera del hogar $y$, a veces, que vivan en dormitorios cercanos a sus fábricas, que acumulen dotes más grandes y que, con ello, sufran menos la presión familiar para casarse temprano y transferir a otra familia sus ingresos y su parte en el capital familiar. En consecuencia, está incrementándose el valor y el uso de las hijas ${ }^{35}$.

\section{POLÍTICA}

Aunque han sucedido muchas cosas desde que Davidson y Reed publicaron su libro en 1998, y aunque algunos colegas tienen una visión menos nacionalista de los hechos a los que ellos se refieren, esto es lo que estos autores dicen en relación a la política en Taiwan:

El partido Guomindang [...], a su favor, lo que [...] había sido un pacto duradero con el pueblo taiwanés, benefactor de la economía más caliente del mundo y de una distribución del ingreso que es una maravilla internacional por su equidad. A cambio de su participación mayoritaria como propietarios en la recientemente industrializada economía, el pueblo taiwanés permaneció por largo tiempo inactivo. La beligerancia latente en su carácter se contuvo a favor del histórico anhelo de los taiwaneses por una vida económica mejor para sus familias. Pero en la década de los 70 pudo advertirse una mayor atención hacia las cuestiones políticas. Los granjeros se inquietaron cuando despacharon a sus varones y mujeres jóvenes hacia los empleos en las fábricas, los cuales aumentaron los ingresos familiares, a la vez que vieron succionar, mediante una variedad de mecanismos fiscales, sus cuantiosas ganancias en la producción agrícola con el fin de alimentar la economía industrial. La juventud taiwanesa mejor -y mejor educada - se unió a otros intelectuales para cuestionar las políticas que habían rechazado de plano ocuparse del ambiente, del desarrollo cultural y de las aspiraciones domésticas de una clase media en crecimiento. ${ }^{36}$

\section{Además,}

Con el levantamiento de la ley marcial en 1987 y la creciente libertad para el disenso, los partidarios de la cultura y de la independencia taiwanesas se hacen oír más y son más numerosos. Los taiwaneses se han aferrado a su propia historia y cultura, a menudo reprimida por el partido Guomindang para fomentar un sentido de identidad con China. En lugar de ser vistas como algo inferior, la lengua y las costumbres taiwanesas son ahora ensalzadas como la cultura de un Taiwan libre. En especial desde la primera elección presidencial en 1996, los taiwaneses se sienten muy orgullosos por su asimilación de los ideales democráticos. La democracia, la libertad y la autonomía política son hoy los nuevos ideales para muchos taiwaneses. ${ }^{37}$

\footnotetext{
${ }^{35}$ Ibidem, p. 184

${ }^{36}$ Ibidem, p. 22.

37 Ibidem, p. 36.
} 


\section{COMENTARIO FINAL}

Puede reiterarse una vez más que el fascinante caso de Taiwan se utiliza aquí como un ejemplo de lo que es una cultura nacional. Como hemos visto en este recorrido, esta dimensión del mundo cultural (Lebenswelt) se compone de sistemas de valor y de uso que, aunque no son compartidos por todos los ciudadanos, sí son compartidos por la mayoría de ellos. Estos sistemas de valor y de uso con frecuencia son cuestionados tanto desde adentro como desde afuera y ciertamente cambian con el paso del tiempo. En los niveles del sentido común y también en el de las ciencias de la cultura, los intentos que se hacen por comprender una cultura nacional contienen un grado considerable de idealización. En fin, bastantes más cosas podrían decirse acerca de estos sistemas. El presente esbozo sólo recorre la superficie, y el libro de Davidson y Reed dice muchas otras cosas, al igual que, desde luego, muchos otros libros. Pero aquí no se sostiene que sobre la base de este esbozo podamos captar exhaustivamente lo que es una cultura nacional, sino únicamente que éste podría ser un buen comienzo. Otros casos particulares y especies de este género pueden ser y serán diferentes y todavía hay mucho trabajo por realizar antes de que quede claro el eidos o esencia universal "nacionalidad". Éste tan sólo ha sido un ejercicio similar al de tratar de comprender qué es un árbol y comenzar por la investigación de un roble sabiendo que es necesario considerar también las palmeras, los pinos, etc. 